\title{
Fatigue Properties of the Ti-Ni Base Shape Memory Alloy Wire
}

\author{
Youngsik Kim \\ Department of Mechanical \& Materials Engineering, Korea Maritime University, \\ Yeongdo-ku, Dongsam-dong, 606-791, Pusan, Korea
}

\begin{abstract}
The effect of the alloy compositions on the cyclic bending fatigue behaviors of the Ti-Ni base shape memory alloy wires was investigated using a rotary bending fatigue tester specially designed for wires. The fatigue test results were discussed in connection with the static tensile properties. The results were summarized as follows. (1) The martensite inducing stress increased with the increasing of the Ni-content. (2) The fatigue life decreased with the increasing of the test temperature and the Ni-content. (3) The fracture pattern resulted from the rotary bending fatigue test has changed from the dimple pattern under the room temperature and small cyclic strain to the quasi-cleavage fracture under the high temperature and large cyclic strain.
\end{abstract}

(Received December 17, 2001; Accepted May 14, 2002)

Keywords: martensitic inducing stress. cyclic strain amplitude. fatigue life curve. quasi-cleavage fracture

\section{Introduction}

The Ti-Ni alloys subjected to cyclic deformation change their deformation behavior, causing for degradation of characteristic functions such as shape memory effect and superelasticity, and finally leads to failure. ${ }^{1,2)}$ Therefore, it is practically very important to understand the fatigue characteristics of the Ti-Ni alloys in order to utilize these functions in various types of applications.

Several papers have been reported so far on the fatigue properties of the $\mathrm{Ti}-\mathrm{Ni}$ alloys with the shapes of plate and bar. ${ }^{3-5)}$ However, the data on the Ti-Ni shape memory alloy wires that are used in most applications such as the fields of sensor, actuator, or medicine are scarcely available except a few for the present. ${ }^{6,7)}$ In the case of wires, the cyclic bending deformation mode is very important, because components made of the shape memory wires receive cyclic bending or twisting in many applications.

The unique characteristics of $\mathrm{Ti}-50.9$ at $\% \mathrm{Ni}$ shape memory alloy wire under the cyclic bending deformation mode were clarified in the previous work by the authors. ${ }^{8)}$ And S. Miyazaki et al. investigated the characteristics of the fatigue life of $\mathrm{Ti}-50$ at $\% \mathrm{Ni}$ and $\mathrm{Ti}-40 \mathrm{Ni}-10 \mathrm{Cu}($ at $\%)$ shape memory alloy wires. ${ }^{9)}$

However, there is yet uncertainty concerning the effect of the variations of the Ni-content in the $\mathrm{Ti}-\mathrm{Ni}$ base shape memory alloy wires.

The present work was intended to find out how the Nicontent affects the deformation behavior and the fatigue lives at the various test temperature for $\mathrm{Ti}-\mathrm{Ni}$ base shape memory alloy wires.

\section{Experimental Details}

The experimental materials were 3 kinds of Ti-Ni base shape memory alloy wires with the compositions of Ti50.0 at $\% \mathrm{Ni}, \mathrm{Ti}-50.5$ at $\% \mathrm{Ni}$ and 50.85 at $\% \mathrm{Ni}$, respectively. The diameter of the wires was $1.0 \mathrm{~mm}$. The wires were cut to $100 \mathrm{~mm}$ length for rotary bending fatigue tests and $40 \mathrm{~mm}$ length for tensile tests. The specimens were annealed at
$673 \mathrm{~K}$ for $3.6 \mathrm{ks}$ followed by water quenching. After the heattreatment, they were polished lightly by emery papers to remove lightly oxidized surface layer, then electropolished. The transformation temperature of the specimens was measured by DSC (Differential Scanning Calorimeter). Table 1 shows the As and Af temperature of each specimen.

For investigating the characteristics of the static deformation behaviors, the tensile tests were first conducted using an Instron 4469 Model with a heating silicon oil chamber. Fatigue tests were carried out using a rotary bending fatigue tester which is specially designed for wires in previous work. ${ }^{8)}$

The cyclic speed was kept constant at $6.7 \mathrm{~Hz}$ and the test temperature changed from 293 to $383 \mathrm{~K}$ with an interval of $30 \mathrm{~K}$. After the fatigue tests, fracture surfaces were investigated by the scanning electron microscope in order to clarify the fracture mode.

\section{Results and Discussion}

In case of $\mathrm{Ti}-\mathrm{Ni}$ base shape memory alloys, the deformations accompany the R-phase (Rhombohedral phase) transition and the subsequent martensitic transformation depending on the thermo-mechanical treatment and Ni-content. ${ }^{10)}$ Figure 1 shows stress-strain curve at $353 \mathrm{~K}$ for $\mathrm{Ti}-50.5$ at $\% \mathrm{Ni}$ alloy.

This curve shows 4 turning points. The points (1) and (2) are analyzed to be associated with the R-phase transition, (3) with the martensitic transformation start and (4) with the permanent deformation start. Figure 2 shows stress-strain curves at various test temperatures for Ti-50.5 at $\% \mathrm{Ni}$ alloy wire. With increasing test temperature, the stress $\left(\sigma_{\mathrm{M}}\right)$ for inducing marten-

Table 1 As and Af temperature of the specimens.

\begin{tabular}{ccc}
\hline \multirow{2}{*}{ Ti-Ni alloys } & \multicolumn{3}{c}{ Temperature (K) } \\
\cline { 2 - 3 } & $A_{\mathrm{s}}$ & $A_{\mathrm{f}}$ \\
\hline Ti-50.0 at\%Ni & 335.8 & 360.8 \\
Ti-50.5 at\% Ni & 329.5 & 358.4 \\
Ti-50.85\% Ni & 310.5 & 333.5 \\
\hline
\end{tabular}




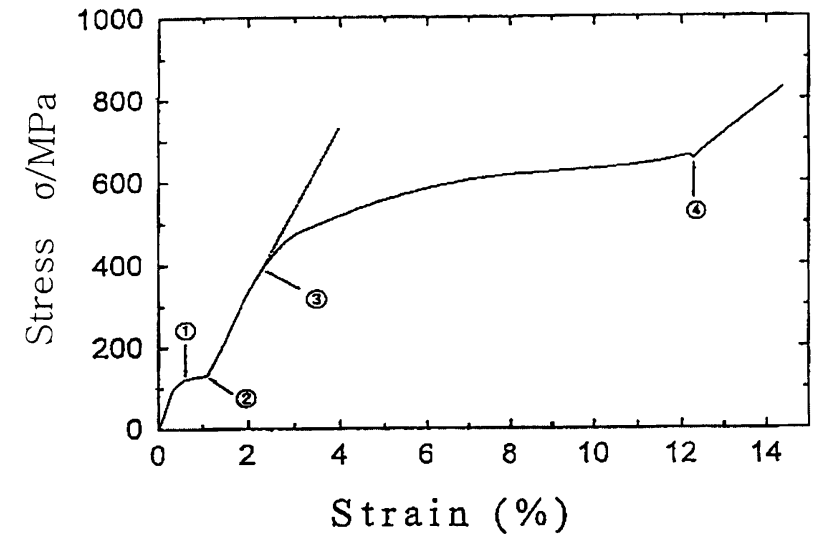

Fig. 1 The stress-strain curve of the Ti-50.5 at $\% \mathrm{Ni}$ alloy at $353 \mathrm{~K}$.

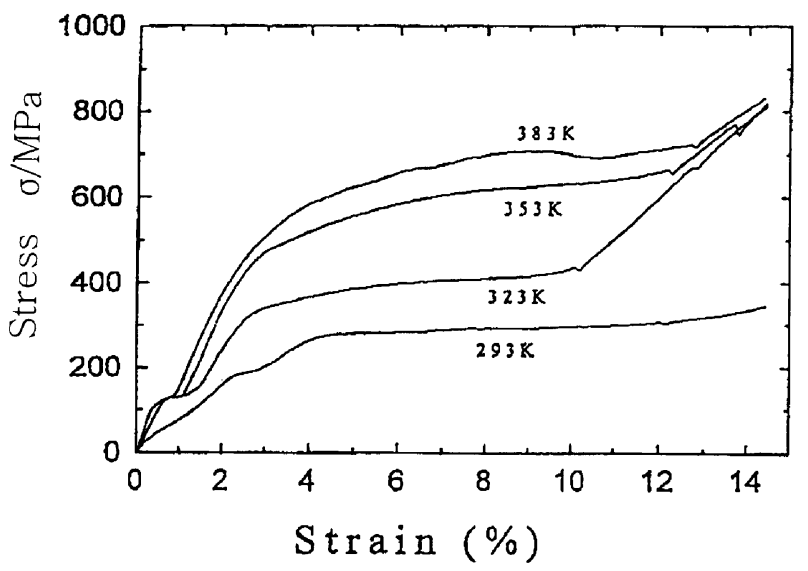

Fig. 2 The stress-strain curve of the Ti-50.5 at $\% \mathrm{Ni}$ alloy.

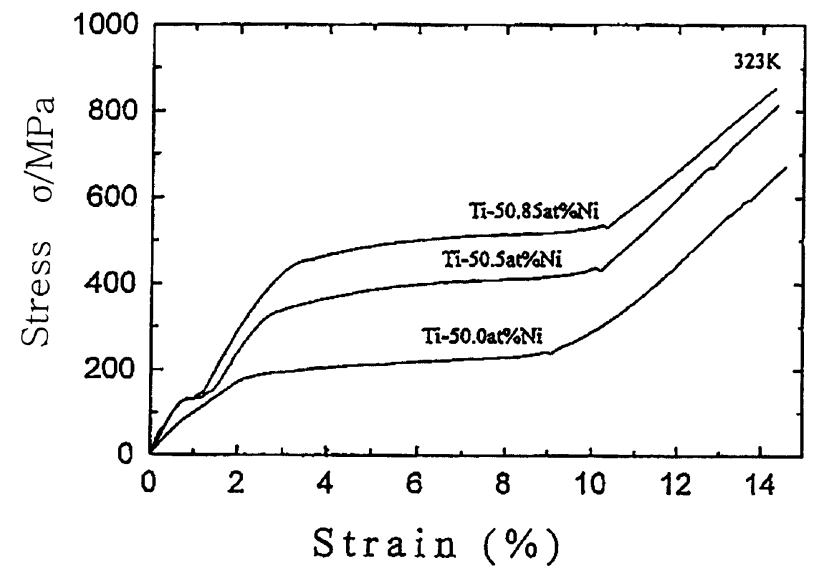

Fig. 3 The stress-strain curve at $323 \mathrm{~K}$.

sitic transformation increases. Moreover, superelastic strain that is the strain to permanent deformation start increases with increasing test temperature.

Figure 3 shows the comparison of the stress-strain curves for 3 different alloy compositions at $323 \mathrm{~K}$. With increasing the Ni-content of the alloy, the $\sigma_{\mathrm{M}}$ and superelastic strain increases.

The strain $\left(\varepsilon_{\mathrm{M}}\right)$ for inducing martensitic transformation and the strain $\left(\varepsilon_{R}\right)$ for inducing R-phase appear as shown in Fig. 4 from the stress-strain curves of Fig. 3. Figure 4 shows that the $\varepsilon_{\mathrm{R}}$ and $\varepsilon_{\mathrm{M}}$ are almost constant at all test temperatures.

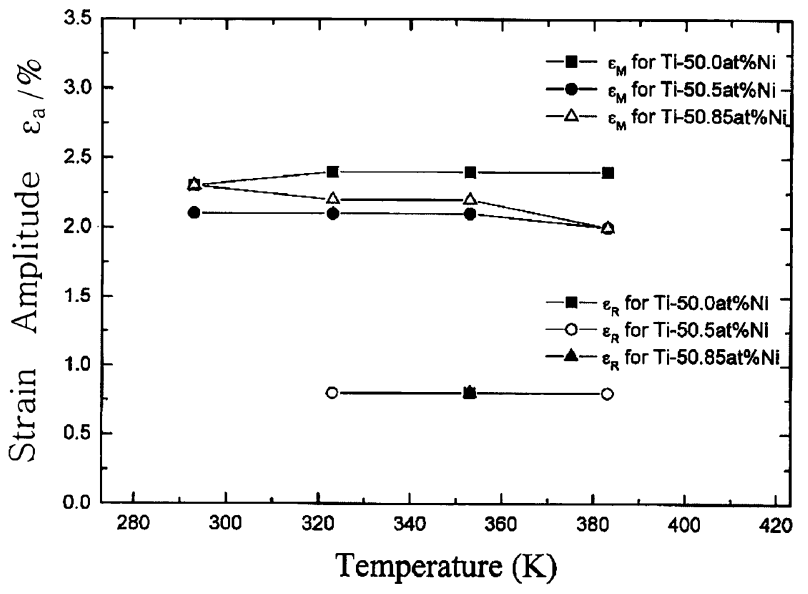

Fig. $4 \varepsilon_{\mathrm{M}}-\varepsilon_{\mathrm{R}}$ as function of temperature.

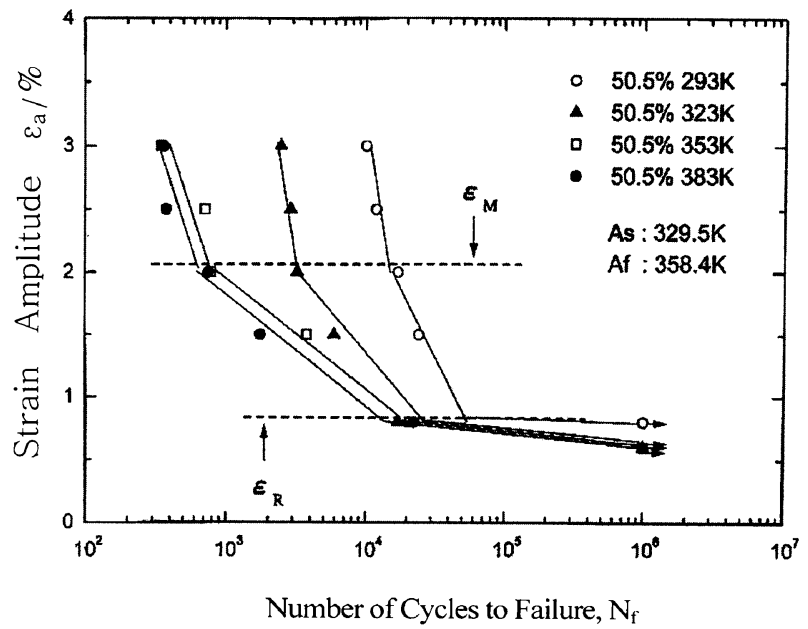

Fig. $5 \varepsilon_{\mathrm{a}}-N_{\mathrm{f}}$ curves in the Ti-50.5 at $\% \mathrm{Ni}$ alloy.

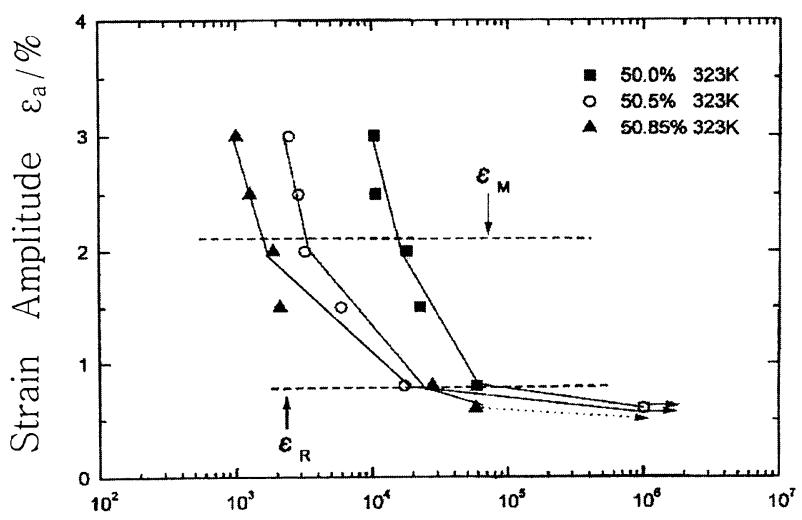

Number of Cycles to Failure, $\mathrm{N}_{\mathrm{f}}$

Fig. $6 \quad \varepsilon_{\mathrm{a}}-N_{\mathrm{f}}$ curves at $323 \mathrm{~K}$.

Fatigue tests were conducted at the four temperatures at which the stress-strain curves were measured. The relationship between strain amplitude $\left(\varepsilon_{\mathrm{a}}\right)$ and fatigue life $\left(N_{\mathrm{f}}\right.$, the number of rotary-bending cycles) of the Ti-50.5 at $\% \mathrm{Ni}$ alloy is shown in Fig. 5. Four $\varepsilon_{\mathrm{a}}-N_{\mathrm{f}}$ curves are shown and each of them consists of three straight line. The reason why the $\varepsilon_{\mathrm{a}}-N_{\mathrm{f}}$ curves have the three region is thought to be caused by occurring of the deformation mode change at the points of $\varepsilon_{\mathrm{M}}$ and $\varepsilon_{\mathrm{R}}$. Those results are similar to previous works by 


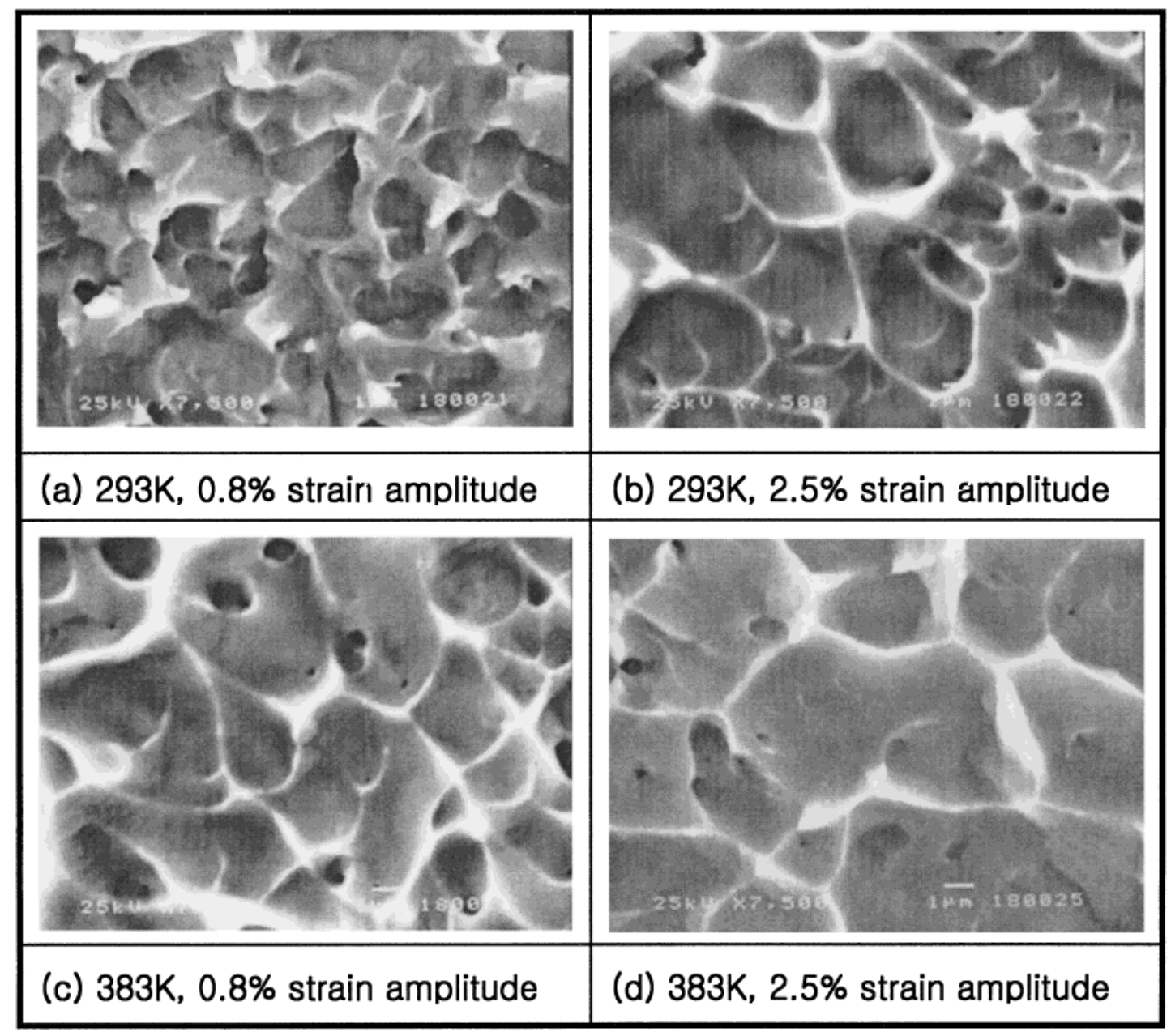

Fig. 7 Fractographs of the Ti-50.85 at\%Ni alloy.

authors and by S. Miyazaki, et al. ${ }^{8,9)}$ In the highest strain amplitude and intermediate strain amplitude regions, the fatigue life increases with decreasing test temperature. However, the fatigue life is almost the same irrespective of test temperature in the lowest strain amplitude region. The $\varepsilon_{\mathrm{M}}$ and $\varepsilon_{\mathrm{R}}$ are also shown by dashed lines in Fig. 5. These strains correspond to the two inflection points in each $\varepsilon_{\mathrm{a}}-N_{\mathrm{f}}$ curve. The temperature dependence of the fatigue life in the highest and intermediate strain amplitude regions is caused by the increasing of the $\sigma_{\mathrm{M}}$ with the test temperature as shown in Fig. 2. The insensitivity to the test temperature in the lowest strain amplitude is due to the full elastic deformation mode in this range.

The effects of the Ni-content on the fatigue life were investigated through the $\varepsilon_{\mathrm{a}}-N_{\mathrm{f}}$ curves of the three alloys with different Ni-content. Figure 6 shows $\varepsilon_{\mathrm{a}}-N_{\mathrm{f}}$ curves of the three alloys with different Ni-content at $323 \mathrm{~K}$. The fatigue life decreases with increasing of the Ni-content in the highest and intermediate strain amplitude. This result comes from the increasing of the $\sigma_{\mathrm{M}}$ with the Ni-content under same strain amplitude in this range as shown in Fig. 3. The narrow gap among the alloys in the lowest strain amplitude is due to the elastic deformation mode in this range in all alloys.

The fracture modes were investigated through the observation of the fracture surfaces using the SEM. Figure 7 shows the comparison of the micrographs of the fractured surfaces under various loading conditions for $\mathrm{Ti}-50.85$ at $\% \mathrm{Ni}$ alloy.
Under same test temperature, the deeper dimples and shear lip patterns are observed at lower strain amplitude as shown in (a) and (b). Moreover, under same strain amplitude, the more quasi-cleavage facets are observed at higher temperature as shown in (b) and (d). This results show that the fracture mode changes from dimple mode under room temperature and low strain amplitude to quasi-cleavage mode under high temperature and high strain amplitude.

The hardening occurs under high temperature and high strain as shown in Fig 2. The quasi-cleavage mode under high temperature and high strain amplitude is thought to be caused by this hardening.

\section{Conclusions}

The static deformation and rotary bending fatigue properties of the Ti-50.0 at $\% \mathrm{Ni}, \mathrm{Ti}-50.5$ at $\% \mathrm{Ni}$ and $\mathrm{Ti}-50.85$ at $\% \mathrm{Ni}$ alloy wires were investigated at various test temperature. Main results are summarized as follows:

(1) The stresses $\left(\sigma_{M}\right)$ for inducing martensitic transformation increased with increasing of the Ni-content while the strain $\left(\varepsilon_{\mathrm{M}}\right)$ for inducing martensitic transformation are hardly affected by the Ni-content.

(2) The relationship between strain amplitude $\left(\varepsilon_{\mathrm{a}}\right)$ and fatigue life $\left(N_{\mathrm{f}}\right)$ consisted of three straight lines with two turning points. In the highest strain amplitude and intermediate 
strain amplitude, the fatigue life decreased with increasing of the test temperature and $\mathrm{Ni}$-content. However, the fatigue lives were hardly affected by the test temperature and $\mathrm{Ni}$ content in the lowest strain amplitude where specimens deform elastically.

(3) The rotary bending fatigue fracture behavior of the Ti-Ni base shape memory alloy wires changed from ductile mode at room temperature and small strain amplitude to quasi-cleavage mode at high temperature and large strain amplitude.

\section{Acknowledgments}

This work was conducted as the succeeding work after the co-working with prof. S. Miyazaki, University of Tsukuba. The author is grateful to prof. S. Miyazaki for supplying the experimental materials and his cooperations.

\section{REFERENCES}

1) S. Miyazaki, T. Imai, Y. Igo and K. Otsuka: Metall. Trans. A17A (1986) $115-120$.

2) S. Miyazaki: Engineering Aspects of Shape Memory Alloys, ed. by T. W. Duerig et al., (Butterworth-Heinemann, 1990) 394-413.

3) K. N. Melton and O. Mercier: Acta Metall. 27 (1979) 137-148.

4) S. Miyazaki, Y. Sugaya and K. Otsuka: Proc. MRS Inter. Mtng. Adv. Mater. Tokyo, Vol. 9, MRS, (1989) 251-262.

5) B. Strnadel, S. Ohashi, H. Ohtsuka, S. Miyazaki and T. Ishihara: Mater. Sci. Eng. A203 (1995) 187-196.

6) J. L. McNichols, Jr., P. C. Brookes and J. S. Cory: J. Appl. Phys. 52 (1981) 7442-7453.

7) H. Tobusi, P. H. Lin, A. Ikai, S. Yamada: Transactions of the Japan Society of Mechanical Engineering 61 (1995) 2355-2361.

8) Y. S. Kim and S. Miyazaki: Fatigue properties of Ti-50.9 at $\% \mathrm{Ni}$ shape memory wires, SMST International Committee (1997) 473-478.

9) S. Miyazaki, K. Mizukoshi, T. Ueki, T. Sakuma and Y. Liu: Mater. Sci. Eng. A273-275 (1999) 658-663.

10) S. Miyazaki and K. Otsuka: Metall. Trans. A17A (1986) 53-63. 